\title{
GLUCOCORTICOID RECEPTOR INVOLVEMENT IN PAIR BONDING IN FEMALE PRAIRIE VOLES: THE EFFECTS OF ACUTE BLOCKADE AND INTERACTIONS WITH CENTRAL DOPAMINE REWARD SYSTEMS
}

\author{
J. T. CURTIS* AND Z. WANG \\ Department of Psychology and Program in Neuroscience, Florida \\ State University, 209 Copeland Avenue, Tallahassee, FL 32306, USA
}

\begin{abstract}
Induction of partner preferences in monogamous prairie voles (Microtus ochrogaster) was used to examine the possibility that blockade of glucocorticoid receptors may be rewarding in females of this species. We first examined the ability of either a mineralocorticoid receptor antagonist (spironolactone) or a glucocorticoid receptor antagonist (RU-486) to induce partner preferences in females. Peripheral administration of either of the antagonists was capable of inducing partner preferences, although the effective dose for RU-486 was an order of magnitude lower than that for spironolactone. We then examined a potential interaction of glucocorticoid receptor with central dopamine in pair bonding by treating females with i.c.v. dopamine receptor antagonists (haloperidol, $\mathrm{SCH} 23390$, or eticlopride) prior to peripheral administration of RU-486. All of the dopamine antagonists were capable of reversing the effects of glucocorticoid receptor blockade on pair bonding. These results establish the ability for acute blockade of glucocorticoid to induce pair bonds in female voles. Further, this effect appears to be mediated via an interaction with central dopamine systems. Together these findings support the possibility that, unlike other model systems, reductions in glucocorticoid receptor activity may enhance reward in female prairie voles. (c) 2005 Published by Elsevier Ltd on behalf of IBRO.
\end{abstract}

Key words: vole, social attachment, corticosterone, stress, Microtus, monogamy.

Pair bonding in prairie voles (Microtus ochrogaster) has been used extensively as a model for investigating the neural basis of social attachment. Both in the field and in the laboratory, this species displays characteristics associated with a monogamous life strategy (Getz et al., 1981), the most prominent of which is the formation of pair bonds between males and females. In the laboratory such pair bonds are manifested by a robust preference to associate with the familiar partner versus with a conspecific stranger (Getz et al., 1981). Importantly, such partner-preferences can be readily quantified in an experimental setting and provide a benchmark by which the effects of experimental manipulations can be assessed.

Recently, increasing attention has been paid to the role of reward processing in pair bond formation. The involve-

${ }^{*}$ Corresponding author. Tel: +1-850-645-5615; fax: +1-850-644-7739. E-mail address: tcurtis@psy.fsu.edu (J. T. Curtis).

Abbreviations: ANOVA, analysis of variance; GR, glucocorticoid receptor; MR, mineralocorticoid receptor; NAcc, nucleus accumbens; VTA, ventral tegmental area.

0306-4522/05\$30.00+0.00 @ 2005 Published by Elsevier Ltd on behalf of IBRO doi:10.1016/j.neuroscience.2005.04.012 ment of the prefrontal cortex (Young et al., 2001), nucleus accumbens (Aragona et al., 2003a; Gingrich et al., 2000; Liu and Wang, 2003; Wang et al., 1999), and ventral pallidum (Lim et al., 2004; Pitkow et al., 2001) in pair bonding supports the suggestion that activation of central "reward circuitry" plays a critical role in pair bond formation (Insel, 2003). Consistent with this notion, mating, which facilitates pair bond formation in this species, also is known to activate brain regions associated with reward processing (Mermelstein and Becker, 1995; Pfaus et al., 1990). Thus, pair bond formation by prairie voles may present an excellent model in which to examine the effects of potentially rewarding stimuli.

A number of studies have identified neurochemical systems that are important for pair bond formation and/or expression. Although there are sex-specific sensitivity differences, neurochemicals associated with pair bonding such as dopamine, vasopressin, and oxytocin appear to act similarly in both sexes in the regulation of social attachment (Cho et al., 1999; Aragona et al., 2003b; Gingrich et al., 2000). An exception to this pattern is found in the effects of the adrenal stress hormone corticosterone for which the effects on pair bonding in monogamous voles are sexually dimorphic (DeVries et al., 1996). Under normal circumstances, the formation of a pair bond by monogamous voles requires many hours of exposure to the partner. However, when corticosterone levels are chronically reduced via adrenalectomy, female prairie voles may form pair bonds within $1 \mathrm{~h}$ of exposure to a male (DeVries et al., 1995). In contrast, acute increases in corticosterone enhance, while adrenalectomy inhibits, the formation of pair bonds in male prairie voles (DeVries et al., 1996).

The information above suggests that, in male voles, increased glucocorticoid receptor activation enhances the reward value of the female. Such a response would be in accord with an extensive literature showing that the effects of stress or elevated corticosterone augment reward (Marinelli and Piazza, 2002). In contrast, adrenalectomy enhances pair bonding in females, suggesting that reductions in glucocorticoid receptor activation may be rewarding in female prairie voles, a suggestion that is contrary to the widely accepted view that corticosterone enhances reward. Most of the work examining the effects of stress on reward processing has been done in males and there are few studies directly comparing the effects of stress on reward processing between males and females. In one such study, Haney et al. (1995) showed that social stress affected self-administration of cocaine similarly in both 
sexes. In general, although several studies reported sex differences in the magnitude of responses to stress, we could find no reports in which stress produced opposite effects on reward processing in males and females in other species. Thus, the first goal of the present study was to test the possibility that reduction in glucocorticoid receptor activation is rewarding in female voles by examining the effects of Type I, mineralocorticoid receptor (MR) and Type II, glucocorticoid receptor (GR) blockade on pair bond formation. Since pair bond formation likely involves a significant reward component, facilitation of pair bonding by GR blockade would provide evidence that GR blockade is rewarding in female prairie voles.

Any effects of GR blockade on reward processing likely involve interactions with central dopamine systems. Dopamine exerts its effects via activation of two families $\left(D_{1}\right.$ and $D_{2}$ ) of receptors (Missale et al., 1998) and a number of studies have examined roles for each in reward processing. For example, the reward associated with self-administered cocaine is reduced by administration of a $D_{1}$ type antagonist into the ventral tegmental area (VTA) in rat (Ranaldi and Wise, 2001). Similarly, blockade of $D_{2}$ type dopamine receptors in the VTA reduces self-administration of morphine (David et al., 2002). Finally, Ikemoto et al. (1997) showed that concurrent activation of both types of dopamine receptors in nucleus accumbens plays a role in reward processing, possibly via a synergistic interaction. These studies show that blockade of either type of dopamine receptor potentially can reduce the reward value of certain stimuli. Thus, in the second part of this study, we test the ability of a variety of dopamine receptor antagonists to counteract the effects of GR blockade, thus providing further evidence that GR blockade may enhance reward in female prairie voles.

\section{EXPERIMENTAL PROCEDURES}

All procedures followed accepted animal care and use guidelines and were approved by the Institutional Animal Care and Use Committee at Florida State University. Care was taken to minimize the number of animals used and to minimize discomfort. All drugs were purchased from Sigma-Aldritch, St. Louis, MO, USA.

Subjects were female offspring of the F4 generation of a laboratory colony of prairie voles (Microtus ochrogaster) originating from Illinois. After weaning at about 21 days of age, pups were kept in same-sex sibling pairs until used in experiments. All animals were housed in plastic shoebox style cages $(29 \times 19 \times 13 \mathrm{~cm})$ under a 14/10-h light/dark cycle with ad libitum food and water. All subjects were about 70 days of age at the time of the experiments.

Neither of the GR antagonists we employed (RU-486 and spironolactone) is water-soluble. Previously we have used sesame oil as a vehicle for non-soluble compounds, however, in those cases, animals received oil at least 1 day prior to experimental manipulations (Curtis et al., 2001). In the present experiment however, animals receiving acute injections of the oil vehicle displayed a partner preference (see results, experiment 1). Thus we instead used propylene glycol as a vehicle for drugs injected i.p. Propylene glycol has previously been used in voles with no apparent effect on behavior (Lonstein, 2002). Dosages were calibrated such that each animal received $100 \mu$ l of propylene glycol/ $40 \mathrm{~g}$ body weight.

\section{Experiment 1}

Females were randomly assigned to experimental groups that received i.p. injections of either vehicle or vehicle containing the GR antagonist RU-486 $(0.4,4.0$ or $40 \mathrm{mg} / \mathrm{kg})$ or the MR antagonist spironolactone $(4.0$ or $40 \mathrm{mg} / \mathrm{kg})$. An additional group received a mixture containing $4.0 \mathrm{mg} / \mathrm{kg}$ of RU-486 and $5.0 \mathrm{mg} / \mathrm{kg}$ of progesterone to control for the possibility that effects of RU-486 were via reduction of progesterone activity. Immediately after drug administration each female was paired with a male for $6 \mathrm{~h}$ of non-sexual cohabitation. Throughout the cohabitation period, the animals' interactions were videotaped (Panasonic time-lapse video recorder (12:1 compression) and low-light camera) for detailed behavioral analysis. Videotapes were subsequently examined to verify the absence of mating.

At the end of the $6 \mathrm{~h}$ cohabitation period, each female was tested for a partner preference. The apparatus for the partner preference test consisted of a central cage $(20 \times 25 \times 45 \mathrm{~cm})$ joined by hollow tubes $(7.5 \times 16 \mathrm{~cm})$ to two identical parallel cages. One of these latter cages contained the familiar male partner, and the other contained an unfamiliar, conspecific male. The males were tethered to restrict their movements to their respective cages and thus had no direct contact with each other. The female was released into the central cage and had free access to all cages. All cages contained food and water. A customized computer program (R. Henderson, Florida State University) using a series of light beams across the connecting tubes was used to monitor movement of the female among the cages. The computer program recorded the amount of time the female spent in each cage and the number of transits between cages. Throughout the test, the animals again were videotaped for behavioral analysis. Variables included the time spent by the female in each male's cage, number of transits between cages (measures of activity to ensure that treatments did not affect locomotor behavior), and the frequency and amount of time the female spent in direct contact with each male. The amount of time females in each group spent in the neutral cage was assessed as a measure of time spent in isolation. Each test lasted for $3 \mathrm{~h}$. For each group, comparisons of time spent in direct contact with the partner vs. that with the stranger (partner preference) were made using a paired $t$-test. Between groups treatment effects on other behavioral measures were evaluated using one-way analysis of variance (ANOVA).

Spironolactone can alter body fluid regulation (Rahmouni et al., 1999), and thus may alter the activity of oxytocin and vasopressin systems, both of which, in turn, can impact pair bonding (Cho et al., 1999). Therefore, any effects of spironolactone on pair bonding could be indirect. Thus, in a separate experiment, 13 female voles were given access to graduated drinking tubes containing $0.15 \mathrm{M} \mathrm{NaCl}$ for 1 week to acclimate them to the presence of a sodium source and then were given a less palatable $0.25 \mathrm{M}$ $\mathrm{NaCl}$ solution for $24 \mathrm{~h}$. Six hour baseline intakes of $0.25 \mathrm{M} \mathrm{NaCl}$ then were recorded. The following day, females were injected with $40 \mathrm{mg} / \mathrm{kg}$ of spironolactone $(n=7)$ or with vehicle $(n=6)$ and $6 \mathrm{~h}$ saline consumption again was recorded. Saline intakes were compared using two-way repeated measures ANOVA.

\section{RESULTS}

As mentioned, all groups that received i.p. injections of sesame oil displayed partner preferences regardless of whether RU-486 was present or not (Table 1). Replacing sesame oil with propylene glycol as an injection vehicle eliminated this confound (Fig. 1).

Both spironolactone and RU-486 were capable of affecting partner preferences in female prairie voles (Fig. 1). As expected vehicle treatment did not produce partner 
Table 1. Comparisons of time spent (mean \pm sem) with the familiar partner vs. a conspecific stranger in groups treated with i.p. sesame oil with or without the GR antagonist RU-486

\begin{tabular}{lllll}
\hline & \multicolumn{2}{l}{ Contact time $(\mathrm{min} / 3 \mathrm{~h})$} & Number $^{\mathrm{a}}$ & $\begin{array}{l}P \\
\text { value }^{\mathrm{b}}\end{array}$ \\
\cline { 2 - 3 } & Partner & Stranger & & \\
\hline Oil control & $60.9 \pm 14.6$ & $14.3 \pm 11.6$ & $7 / 9$ & $<0.05$ \\
RU-486 $(4 \mathrm{mg} / \mathrm{kg})$ & $63.9 \pm 11.5$ & $10.6 \pm 3.9$ & $7 / 8$ & $<0.01$ \\
RU-486 $(40 \mathrm{mg} / \mathrm{kg})$ & $56.5 \pm 9.8$ & $11.2 \pm 7.5$ & $6 / 7$ & $<0.05$ \\
\hline
\end{tabular}

${ }^{a}$ Number of pairs displaying a partner preference/number of pairs tested.

${ }^{b}$ Significance level for results of $t$-tests comparing time spent with the partner vs. the stranger under each condition.

preferences after $6 \mathrm{~h}$ of non-sexual cohabitation $(t=0.54$, $P=0.61)$. Blockade of $\mathrm{GRs}$ with the highest dose $(40 \mathrm{mg} /$ $\mathrm{kg}$ ) of either drug induced a significant preference for the familiar partner versus the conspecific stranger (RU-486, $t=1.90, P<0.05$; spironolactone, $t=4.57, P<0.01$ ). RU-486 also was capable of partner preference induction at $4.0 \mathrm{mg} /$ $\mathrm{kg}$, both with $(t=2.80, P<0.03)$ and without $(t=7.23$, $P<0.001)$ progesterone, but not at $0.4 \mathrm{mg} / \mathrm{kg} \quad(t=0.91$,
$P=0.39$ ). Spironolactone was ineffective at a dose of $4.0 \mathrm{mg} / \mathrm{kg}(t=1.53, P=0.17)$.

Treatment effects were not found for other social factors or for non-social factors such as locomotor activity. There were no group differences in combined time spent in contact with stimulus animals $\left(F_{5,47}=0.75, P=0.59\right)$, time spent in the center cage $\left(F_{5,46}=1.9, P=0.11\right)$, or locomotor activity $\left(F_{5,46}=0.27, P=0.93\right)$. MR blockade did not induce saline intake. There were no group differences in baseline saline intake $\left(F_{1,22}=0.07, P=0.80\right)$ or intake after spironolactone treatment $\left(F_{1,22}=0.38, P=0.54\right)$, and no interaction $\left(F_{12,22}=0.28, P=0.60\right)$.

\section{Experiment 2}

The ability of RU-486 to induce pair bonds suggests that GR blockade is rewarding in female prairie voles. We tested this possibility further by pre-treating females with dopamine receptor antagonists prior to RU-486 treatment. Females were outfitted with guide cannulae aimed at the lateral ventricles (stereotaxic coordinates from Bregma: $1.8 \mathrm{~mm}$ caudal, $1.1 \mathrm{~mm}$ lateral, $2.0 \mathrm{~mm}$ ventral) and allowed 3 days of surgical recovery. On the test day, animals

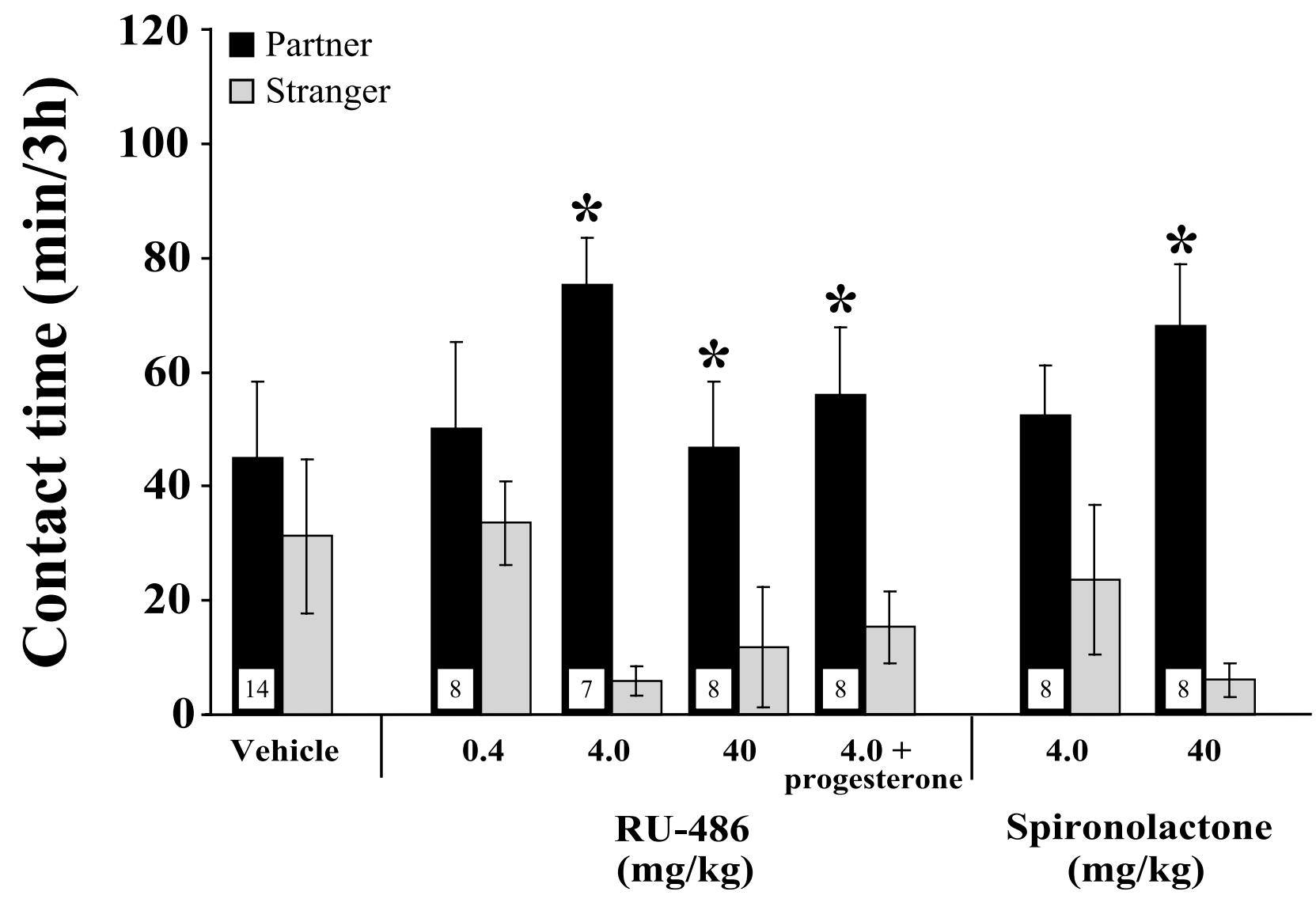

Fig. 1. Blockade of either GR or MR induced pair bonds in monogamous voles. Females were treated with RU-486, a GR antagonist, or with spironolactone, a MR antagonist, and then paired with a male for $6 \mathrm{~h}$. In a subsequent choice test, females treated with vehicle or with the lowest doses of GR antagonists were equally likely to associate with an unfamiliar male as with the familiar partner, while females treated with higher doses displayed a preference for affiliation with the partner. GR-blockade-induced partner preferences were unaffected by concurrent administration of $5 \mathrm{mg} / \mathrm{kg}$ of progesterone. * Significantly more time spent with the familiar partner than with a conspecific stranger. Group sizes are shown within the first bar for each group. 
were randomly assigned to groups that received i.c.v. administration of vehicle $(200 \mathrm{nl}$ of a salt solution isotonic for $\mathrm{Na}^{+}, \mathrm{Mg}^{++}, \mathrm{Ca}^{++}$, and $\mathrm{K}^{+}$), or of vehicle containing the general dopamine receptor antagonist haloperidol (200 $\mathrm{ng}$ ), the $\mathrm{D}_{1}$ sub-type dopamine receptor antagonist $\mathrm{SCH}$ 23390 (50 or $200 \mathrm{ng}$ ), or the $\mathrm{D}_{2}$ sub-type antagonist eticlopride $(50,200$, or $350 \mathrm{ng})$. This treatment was followed immediately by i.p. administration of $4.0 \mathrm{mg} / \mathrm{kg}$ RU-486 and each subject then was paired with a male for $6 \mathrm{~h}$ and tested for a partner preference as in experiment 1.

\section{RESULTS}

As expected from the results of experiment $1,4.0 \mathrm{mg} / \mathrm{kg}$ of RU-486 induced partner preferences when paired with i.c.v. administration of vehicle $(t=3.41, P<0.01$; Fig. 2). When RU-486 treatment was paired with central administration of haloperidol, females spent equal amounts of time with stranger as with the partner $(t=0.85, P=0.42)$. We then examined the potential roles of dopamine receptor sub-types in GR-blockade-induced pair bonding. Treating females with $\mathrm{SCH} 23390$, a $D_{1}$ sub-type dopamine receptor antagonist, prior to RU-486 administration, blocked partner preferences at $200 \mathrm{ng}(t=0.43, P=0.68)$ but not at $50 \mathrm{ng}$ $(t=4.18, P<0.01)$. RU-486-induction of partner preferences also was inhibited by central administration of eticlopride, a $D_{2}$ sub-type dopamine receptor antagonist, at a dose of $350 \mathrm{ng}(t=0.36, P=0.72)$, but not at lower doses (200 ng; $t=3.43, P<0.01$ and $50 \mathrm{ng} ; t=2.09, P<0.5$ ). No treatment effects were found for other social behaviors (total contact time, $F_{6,53}=0.08, P=0.57$; time spent in central cage, $F_{6,53}=0.75, P=0.61$ ) or for number of cage entries $\left(F_{6,53}=0.52, P=0.79\right)$.

\section{DISCUSSION}

Stress can significantly impact pair bond formation in monogamous voles (DeVries et al., 1996), presumably via changes in circulating levels of corticosterone. In female prairie voles, stress and the associated increases in corticosterone inhibit the formation of pair bonds (DeVries et al., 1995, 1996) whereas adrenalectomy facilitates pair bond formation (DeVries et al., 1995). Moreover, upon exposure to a male, sexually naïve prairie vole females experience a significant decline in circulating corticosterone within $1 \mathrm{~h}$ (DeVries et al., 1995). These results suggest that reduction of GR activation is important in the formation of pair bonds by female voles. Here we extend these findings by showing that acute blockade of GRs also is capable of facilitating pair bond formation. We further show that dopamine receptor antagonists can block the effects of a GR antagonist on pair bonding. Together these observations suggest that, in female voles, acute reductions in GR activation may increase the reward value associated with the male.

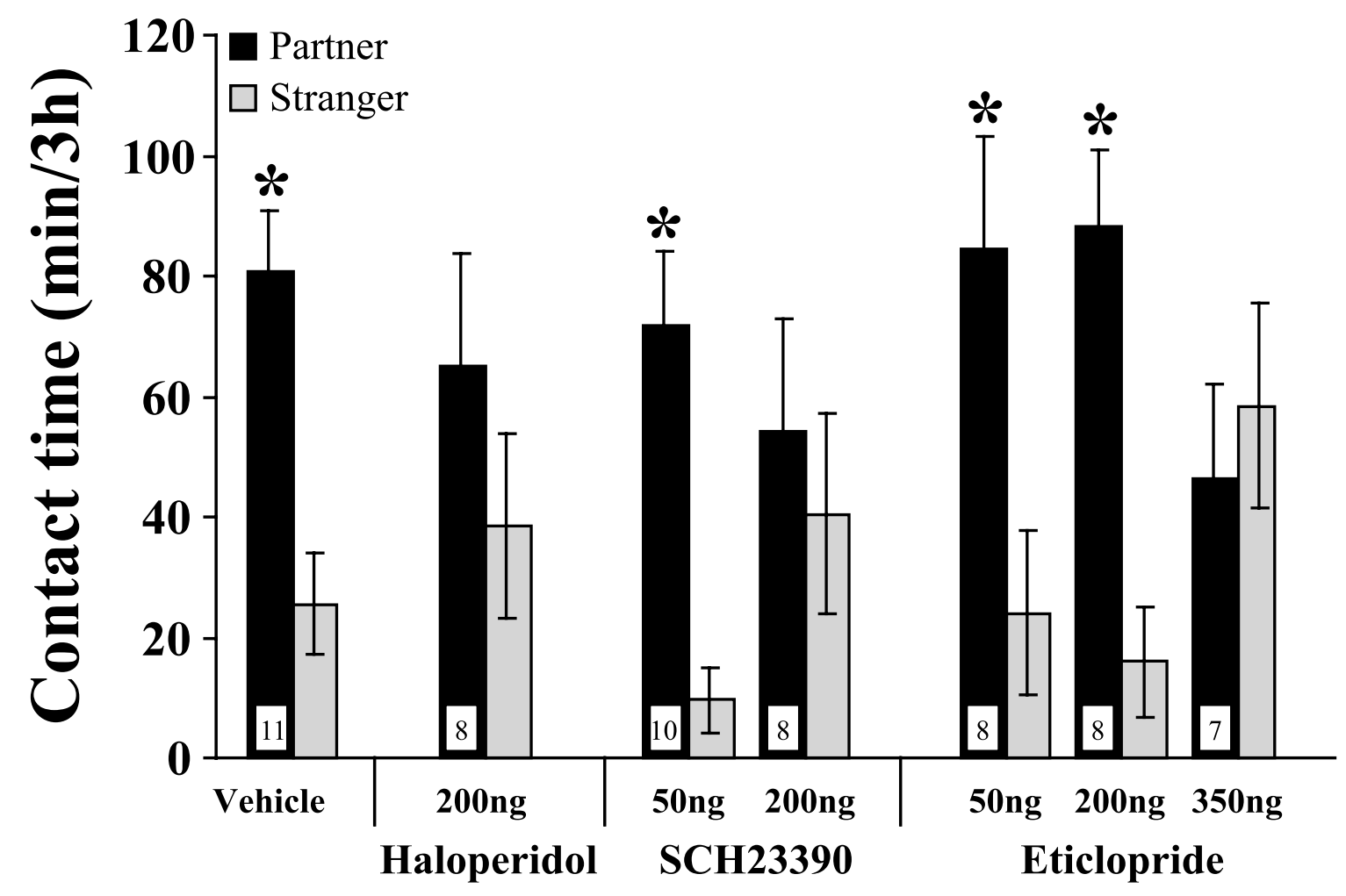

Fig. 2. Pair bond induction after GR blockade involves central dopamine systems. Female prairie voles were given i.c.v. administration of vehicle or vehicle containing one of three dopamine receptor antagonists. Subjects were then treated with $\mathrm{RU}-486$ intraperitoneally at a dose (4.0 $\mathrm{mg} / \mathrm{kg})$ previously shown to cause pair bond induction. All three dopamine receptor antagonists were capable of inhibiting pair bonds induced by GR blockade.

* Significantly more time spent with the familiar partner than with a conspecific stranger. Group sizes are shown within the first bar for each group. 


\section{GR blockade and pair bonding}

Corticosterone effects are the result of binding to two types of receptors (Douma et al., 1998): a high affinity (Type I) MR and a lower affinity (Type II) GR. High basal levels of circulating corticosterone, such as are found in monogamous voles (Taymans et al., 1997), likely result in activation of both types of GRs (de Kloet et al., 1993), while activation of both types of GRs is reduced in adrenalectomized voles (Hastings et al., 1999). Although activation of the two types of GRs produces opposing actions on a variety of measures in other species (de Kloet et al., 1993), we found that either MR or GR receptor blockade could facilitate pair bonding in the female voles.

It must be noted that GR blockade could affect pair bonding indirectly. For example, blockade of MR can alter mechanisms involved in body fluid regulation (Rahmouni et al., 1999). These actions, in turn, could affect pair bonding by altering central vasopressin and/or oxytocin activity that is implicated both in fluid regulation and in pair bond formation (Cho et al., 1999). The fact that we did not find changes in saline ingestion after spironolactone treatment suggests that changes in body fluids were not a significant factor. It also should be noted that, in addition to blocking GR, RU-486 has anti-progesterone effects (Truss et al., 1994), while spironolactone has anti-androgen effects (Yamasaki et al., 2004). As reflex ovulators, prairie voles do not experience cyclic fluctuations in progesterone and functional corpora lutea are not observed until at least $10 \mathrm{~h}$ after mating (Carter et al., 1989). Even $48 \mathrm{~h}$ exposure to males and male-associated stimuli was insufficient to induce elevation of circulating progesterone (Cohen-Parsons and Carter, 1988). These results suggest that a pair bond can be formed in the absence of increases in circulating progesterone. Similarly, decreases in progesterone appear to have minimal impact on pair bond formation. Under cohabitation conditions of the same duration as used in the present study, ovariectomized females did not form partner preferences (Williams et al., 1992). Further, in the present study, RU-486 induction of pair bonding was unimpaired by co-administration of progesterone at a dose approximately two- to four-fold higher than is typically used to induce lordosis behavior in estrogen primed rats (Pfaus et al., 2000; Witt and Insel, 1991). This suggests that the effects of RU-486 could not be attributed solely to its anti-progesterone activity. Finally, other behaviors associated with pair bond formation, such as increased aggression and decreased affiliation with strangers are unaffected by ovariectomy (Bowler et al., 2002). Thus, it is unlikely that the pair bonding responses seen in the present study result from the anti-gonadal-hormone activities of RU-486 and spironolactone.

Spironolactone induced significant changes in a complex suite of behaviors, suggesting that it is acting centrally. The highest densities of MR within the brain are consistently found in the hippocampus (Ahima et al., 1991; Herman, 1993), suggesting this brain region as the obvious site for MR effects. Although a direct role for the hippocampus in pair bonding has not been examined, it is known that this region is not involved in mate recognition in voles (Demas et al., 1997). Nonetheless, MR blockade within the hippocampus could induce pair bond formation indirectly by altering the activity of the VTA (Floresco et al., 2001; Legault et al., 2000), a major source of central dopamine which, in turn, is known to play a role in pair bonding. MR also are found in the accessory olfactory system and medial amygdala, lateral septum, bed nucleus of the stria terminalis, ventral pallidum, and nucleus accumbens (Ahima et al., 1991), each of which has previously been implicated in pair bond formation (Curtis et al., 2001; Gingrich et al., 2000; Lim and Young, 2004; Liu et al., 2001; Wang et al., 1997).

Basal circulating corticosterone levels are approximately 10-fold higher in prairie voles than in promiscuous vole species or in rats or mice (Carter et al., 1995; Hastings et al., 1999; Taymans et al., 1997). Nonetheless, prairie voles are capable of further stress-induced increases in circulating corticosterone (Taymans et al., 1997; DeVries et al., 1995) which tend to act primarily on GR (Burgess and Handa, 1992; de Kloet et al., 1993). As with MR, GR are widely distributed throughout the brain and in many cases the distributions of the two GR types overlap (Ahima et al., 1991; Ahima and Harlan, 1990). One region in which there may be some difference in the relative densities of the two types of GRs is the shell portion of NAcc (Ahima et al., 1991; Ahima and Harlan, 1990), an area strongly implicated in pair bonding (Aragona et al., 2003a; Gingrich et al., 2000). This suggests that GR blockade may affect pair bonding via interaction with central dopamine "reward" pathways.

\section{Interaction with central dopamine}

GR-blockade induction of pair bond formation suggests that such blockade enhances the effects of rewarding stimuli in female voles. This is in contrast to the widely accepted view that corticosterone enhances the rewarding properties of stimuli such as psychostimulant drugs (Marinelli and Piazza, 2002). Experimental examination of the effects of stress on reward processing has not been attempted in voles, thus it is unknown whether the same responses occur in both sexes in this species as are seen in other laboratory rodents. If stress enhances rewarding stimuli in male voles as is seen in other rodents, while reducing the effects of rewarding stimuli in females, these results could account for the sexual dimorphism in the effects of stress on pair bonding in monogamous voles (DeVries et al., 1996).

The validity of the proposal that GR blockade may interact with central reward pathways to affect pair bonding depends on establishing an interaction between GR blockade and central dopamine systems. Our finding that the effects of RU-486 on pair bonding are antagonized by dopamine receptor blockade suggests that corticosterone indeed may interact with central dopamine systems during social bonding. The ability of eticlopride to block GR blockade-induced pair bonds was not unexpected since it is well-established that $D_{2}$ receptor activation plays an important role in pair bond formation (Aragona et al., 2003b; 
Gingrich et al., 2000; Wang et al., 1999). Physical and social stress can alter dopamine release in NAcc (Abercrombie et al., 1989; Tidey and Miczek, 1996) which has been implicated in pair bonding in prairie voles (Aragona et al., 2003a). While it is unlikely that MR blockade exerts its effects within NAcc (Marinelli et al., 1998), there is evidence that GR and the dopamine system may interact in this brain region. Thus corticosterone could affect pair bonding via effects in this region

The ability of a $D_{1}$ dopamine receptor antagonist to inhibit pair bonding induced by RU-486 was somewhat unexpected. A previous study found that $D_{1}$ receptor blockade did not interfere with mating-induced partner preference formation in female prairie voles (Wang et al., 1999). Several explanations, such as drug dose and route of administration, may account for this apparent discrepancy between the previous (Wang et al., 1999) and present studies. In addition, a $24 \mathrm{~h}$ paradigm that incorporated mating was employed in the previous study while a $6 \mathrm{~h}$ paradigm without mating was used in the present study. Since it is unclear how mating and GR blockade may differ with respect to interactions with other neurotransmitter systems implicated in pair bonding, it is possible that the mechanisms by which mating and GR blockade induce pair bonds differ.

The VTA is a major source of dopamine within the brain and may be an important point of convergence between stress-mediated and reward-mediated effects on pair bonding. Saal et al. (2003) demonstrated substantial synaptic reorganization within the VTA after exposure to stress that could be blocked by RU-486. Similar changes have been shown to occur within $2 \mathrm{~h}$ after amphetamine treatment (Faleiro and Kauer, 2003), placing this phenomenon within a timeframe appropriate for involvement in pair bonding. Amphetamine and cocaine both produce changes in glutamate release in VTA that are associated with behavioral sensitization (Kalivas and Duffy, 1998; Wolf and Xue, 1998) and that appear to be mediated primarily via a $D_{1}$ (Kalivas and Duffy, 1998; Ranaldi and Wise, 2001; Wolf and Xue, 1998), but not $D_{2}$ (Wolf and Xue, 1998), mechanism, suggesting that the effects of $\mathrm{SCH} 23390$ on RU-486-induced pair bonds may be mediated via the VTA. This notion is further supported by the finding that intra-VTA blockade of $D_{1}$ receptors reduced the reward value of self-administered cocaine (Ranaldi and Wise, 2001).

\section{Other considerations}

The observation that i.p. sesame oil injections alone could induce partner preference formation must be noted. Nutrients injected into the peritoneal cavity rapidly reach circulation (Gilsdorf et al., 1985; Mahedero et al., 1992; Torres et al., 1978). In the case of oil, it is possible that such absorption may mimic the effects of oil ingestion. Ingestion of oil likely has a dopamine-mediated reward component since oil ingestion can induce a conditioned place preference that is blocked by haloperidol (Imaizumi et al., 2000). Important here is that post-absorptive effects of nutrient ingestion also have a reward component (Lucas and
Sclafani, 1989). The expression of partner preferences after i.p. sesame oil injections would be consistent with activation of reward pathways. Importantly, partner preferences were not displayed after propylene glycol administration. This suggests that caution must be taken in designing and interpreting the results of studies in which females are estrogen primed to induce sexual receptivity since oil is often the vehicle for such treatments.

Finally, as mentioned earlier, the possibility that GR blockade may enhance reward in female voles would be unusual relative to other models. What might account for such a difference? It has been shown that the neuropeptide oxytocin interacts with systems that are involved in reward processing (Sarnyai et al., 1992) and oxytocin may exert its effects on pair bonding by modulating reward processing (Young et al., 2001). Females of monogamous prairie voles differ from those of promiscuous voles in the distribution of oxytocin receptors (Insel and Shapiro, 1992) and concurrent activation of both oxytocin and dopamine receptors is necessary for pair bond formation (Liu and Wang, 2003). Thus, the potentially unique oxytocin system displayed by prairie voles could account for the possibility that blockade of GR may be rewarding in female prairie voles.

Acknowledgments-We thank Mr. Michael Smeltzer, Mr. Kyle Gobrogge, and Dr. Kathleen Curtis for helpful suggestions. This work was supported by National Institutes of Health grants NICHD 40722 (J.T.C.) and NIMH 58616 and NIMH 66734 (Z.W.).

\section{REFERENCES}

Abercrombie ED, Keefe KA, DiFrischia DS, Zigmond MJ (1989) Differential effect of stress on in vivo dopamine release in striatum, nucleus accumbens, and medial frontal cortex. J Neurochem 52 : 1655-1658.

Ahima R, Krozowski Z, Harlan R (1991) Type I corticosteroid receptorlike immunoreactivity in the rat CNS: distribution and regulation by corticosteroids. J Comp Neurol 313:522-538.

Ahima RS, Harlan RE (1990) Charting of type II glucocorticoid receptor-like immunoreactivity in the rat central nervous system. Neuroscience 39:579-604.

Aragona BJ, Liu Y, Curtis JT, Stephan FK, Wang Z (2003a) A critical role for nucleus accumbens dopamine in partner-preference formation in male prairie voles. J Neurosci 23:3483-3490.

Aragona BJ, Liu Y, Wang ZX (2003b) Nucleus accumbens dopamine is important for social choice and the maintenance of social bonds. Soc Neurosci Abstr Program number 757.7.

Bowler CM, Cushing BS, Carter CS (2002) Social factors regulate female-female aggression and affiliation in prairie voles. Physiol Behav 76:559-566.

Burgess LH, Handa RJ (1992) Chronic estrogen-induced alterations in adrenocorticotropin and corticosterone secretion, and glucocorticoid receptor-mediated functions in female rats. Endocrinology 131:1261-1269.

Carter CS, DeVries AC, Taymans SE, Roberts RL, Williams JR, Chrousos GP (1995) Adrenocorticoid hormones and the development and expression of mammalian monogamy. Ann N Y Acad Sci 771:82-91.

Carter CS, Witt DM, Manock SR, Adams KA, Bahr JM, Carlstead K (1989) Hormonal correlates of sexual behavior and ovulation in male-induced and postpartum estrus in female prairie voles. Physiol Behav 46:941-948. 
Cho MM, DeVries AC, Williams JR, Carter CS (1999) The effects of oxytocin and vasopressin on partner preferences in male and female prairie voles (Microtus ochrogaster). Behav Neurosci 113: 1071-1079.

Cohen-Parsons M, Carter CS (1988) Males increase progestin receptor binding in brain of female voles. Physiol Behav 42:191-197.

Curtis JT, Liu Y, Wang Z (2001) Lesions of the vomeronasal organ disrupt mating-induced pair bonding in female prairie voles (Microtus ochrogaster). Brain Res 901:167-174.

David V, Durkin TP, Cazala P (2002) Differential effects of the dopamine D2/D3 receptor antagonist sulpiride on self-administration of morphine into the ventral tegmental area or the nucleus accumbens. Psychopharmacology (Berl) 160:307-317.

de Kloet ER, Oitzl MS, Joels M (1993) Functional implications of brain corticosteroid receptor diversity. Cell Mol Neurobiol 13:433-455.

Demas GE, Williams JM, Nelson RJ (1997) Amygdala but not hippocampal lesions impair olfactory memory for mate in prairie voles (Microtus ochrogaster). Am J Physiol 273:R1683-R1689.

DeVries AC, DeVries MB, Taymans S, Carter CS (1995) Modulation of pair bonding in female prairie voles (Microtus ochrogaster) by corticosterone. Proc Natl Acad Sci U S A 92:7744-7748.

DeVries AC, DeVries MB, Taymans SE, Carter CS (1996) The effects of stress on social preferences are sexually dimorphic in prairie voles. Proc Natl Acad Sci U S A 93:11980-11984.

Douma BR, Korte SM, Buwalda B, la Fleur SE, Bohus B, Luiten PG (1998) Repeated blockade of mineralocorticoid receptors, but not of glucocorticoid receptors impairs food rewarded spatial learning. Psychoneuroendocrinology 23:33-44.

Faleiro L, Kauer J (2003) Synaptic plasticity at glutamergic synapses on dopamine neurons in the ventral tegmental area (VTA) is detected within two hours of amphetamine injection. Soc Neurosci Abstr Program number 319.8.

Floresco SB, Todd CL, Grace AA (2001) Glutamatergic afferents from the hippocampus to the nucleus accumbens regulate activity of ventral tegmental area dopamine neurons. J Neurosci 21: 4915-4922.

Getz LL, Carter CS, Gavish L (1981) The mating system of the prairie vole, Microtus ochrogaster: field and laboratory evidence for pairbonding. Behav Ecol Sociobiol 8:189-194.

Gilsdorf RB, Selby RR, Schon DA, Potter JD (1985) Total nutritional support through the peritoneal cavity. J Am Coll Nutr 4:461-469.

Gingrich B, Liu Y, Cascio C, Wang Z, Insel TR (2000) Dopamine D2 receptors in the nucleus accumbens are important for social attachment in female prairie voles (Microtus ochrogaster). Behav Neurosci 114:173-183.

Haney M, Maccari S, Le Moal M, Simon H, Piazza PV (1995) Social stress increases the acquisition of cocaine self-administration in male and female rats. Brain Res 698:46-52.

Hastings NB, Orchinik M, Aubourg MV, McEwen BS (1999) Pharmacological characterization of central and peripheral type I and type II adrenal steroid receptors in the prairie vole, a glucocorticoidresistant rodent. Endocrinology 140:4459-4469.

Herman JP (1993) Regulation of adrenocorticosteroid receptor mRNA expression in the central nervous system. Cell Mol Neurobiol 13:349-372.

Ikemoto S, Glazier BS, Murphy JM, McBride WJ (1997) Role of dopamine D1 and D2 receptors in the nucleus accumbens in mediating reward. J Neurosci 17:8580-8587.

Imaizumi M, Takeda M, Fushiki T (2000) Effects of oil intake in the conditioned place preference test in mice. Brain Res 870:150-156.

Insel TR (2003) Is social attachment an addictive disorder? Physiol Behav 79:351-357.

Insel TR, Shapiro LE (1992) Oxytocin receptor distribution reflects social organization in monogamous and polygamous voles. Proc Natl Acad Sci U S A 89:5981-5985.

Kalivas PW, Duffy P (1998) Repeated cocaine administration alters extracellular glutamate in the ventral tegmental area. J Neurochem 70:1497-1502.
Legault M, Rompre PP, Wise RA (2000) Chemical stimulation of the ventral hippocampus elevates nucleus accumbens dopamine by activating dopaminergic neurons of the ventral tegmental area. J Neurosci 20:1635-1642.

Lim MM, Wang ZX, Olazabel DE, Ren XH, Terwilliger EF, Young LJ (2004) Enhanced partner preference in a promiscuous species by manipulating the expression of a single gene. Nature 429: 754-757.

Lim MM, Young LJ (2004) Vasopressin-dependent neural circuits underlying pair bond formation in the monogamous prairie vole. Neuroscience 125:35-45.

Liu Y, Curtis JT, Wang Z (2001) Vasopressin in the lateral septum regulates pair bond formation in male prairie voles (Microtus ochrogaster). Behav Neurosci 115:910-919.

Liu Y, Wang ZX (2003) Nucleus accumbens oxytocin and dopamine interact to regulate pair bond formation in female prairie voles. Neuroscience 121:537-544.

Lonstein JS (2002) Effects of dopamine receptor antagonism with haloperidol on nurturing behavior in the biparental prairie vole. Pharmacol Biochem Behav 74:11-19.

Lucas F, Sclafani A (1989) Flavor preferences conditioned by intragastric fat infusions in rats. Physiol Behav 46:403-412.

Mahedero G, Moran JM, Salas J, Blanco M (1992) Absorption of Intralipid and interferences from nutrients infused into the peritoneal cavity of the rat. Am J Surg 164:45-50.

Marinelli M, Aouizerate B, Barrot M, Le Moal M, Piazza PV (1998) Dopamine-dependent responses to morphine depend on glucocorticoid receptors. Proc Natl Acad Sci U S A 95:7742-7747.

Marinelli M, Piazza PV (2002) Interaction between glucocorticoid hormones, stress and psychostimulant drugs. Eur J Neurosci 16:387-394.

Mermelstein PG, Becker JB (1995) Increased extracellular dopamine in the nucleus accumbens and striatum of the female rat during paced copulatory behavior. Behav Neurosci 109:354-365.

Missale C, Nash SR, Robinson SW, Jaber M, Caron MG (1998) Dopamine receptors: from structure to function. Physiol Rev 78:189-225.

Pfaus JG, Damsma G, Nomikos GG, Wenkstern DG, Blaha CD, Phillips AG, Fibiger HC (1990) Sexual behavior enhances central dopamine transmission in the male rat. Brain Res 530:345-348.

Pfaus JG, Smith WJ, Byrne N, Stephens G (2000) Appetitive and consummatory sexual behaviors of female rats in bilevel chambers. II. Patterns of estrus termination following vaginocervical stimulation. Horm Behav 37:96-107.

Pitkow LJ, Sharer CA, Ren X, Insel TR, Terwilliger EF, Young LJ (2001) Facilitation of affiliation and pair-bond formation by vasopressin receptor gene transfer into the ventral forebrain of a monogamous vole. J Neurosci 21:7392-7396.

Rahmouni K, Barthelmebs M, Grima M, Imbs JL, Wybren De J (1999) Brain mineralocorticoid receptor control of blood pressure and kidney function in normotensive rats. Hypertension 33:1201-1206.

Ranaldi R, Wise RA (2001) Blockade of D1 dopamine receptors in the ventral tegmental area decreases cocaine reward: possible role for dendritically released dopamine. J Neurosci 21:5841-5846.

Saal D, Dong Y, Bonci A, Malenka RC (2003) Drugs of abuse and stress trigger a common synaptic adaptation in dopamine neurons. Neuron 37:577-582.

Sarnyai Z, Szabo G, Kovacs GL, Telegdy G (1992) Opposite actions of oxytocin and vasopressin in the development of cocaine-induced behavioral sensitization in mice. Pharmacol Biochem Behav 43: 491-494.

Taymans SE, DeVries AC, DeVries MB, Nelson RJ, Friedman TC, Castro M, Detera-Wadleigh S, Carter CS, Chrousos GP (1997) The hypothalamic-pituitary-adrenal axis of prairie voles (Microtus ochrogaster): evidence for target tissue glucocorticoid resistance. Gen Comp Endocrinol 106:48-61.

Tidey JW, Miczek KA (1996) Social defeat stress selectively alters mesocorticolimbic dopamine release: an in vivo microdialysis study. Brain Res 721:140-149. 
Torres IJ, Litterst CL, Guarino AM (1978) Transport of model compounds across the peritoneal membrane in the rat. Pharmacology $17: 330-340$

Truss M, Bartsch J, Beato M (1994) Antiprogestins prevent progesterone receptor binding to hormone responsive elements in vivo. Proc Natl Acad Sci U S A 91:11333-11337.

Wang Z, Hulihan TJ, Insel TR (1997) Sexual and social experience is associated with different patterns of behavior and neural activation in male prairie voles. Brain Res 767:321-332.

Wang Z, Yu G, Cascio C, Liu Y, Gingrich B, Insel TR (1999) Dopamine D2 receptor-mediated regulation of partner preferences in female prairie voles (Microtus ochrogaster): a mechanism for pair bonding? Behav Neurosci 113:602-611.

Williams JR, Catania KC, Carter CS (1992) Development of partner preferences in female prairie voles (Microtus ochrogaster): the role of social and sexual experience. Horm Behav 26:339349.

Witt DM, Insel TR (1991) A selective oxytocin antagonist attenuates progesterone facilitation of female sexual behavior. Endocrinology 128:3269-3276

Wolf ME, Xue CJ (1998) Amphetamine and D1 dopamine receptor agonists produce biphasic effects on glutamate efflux in rat ventral tegmental area: modification by repeated amphetamine administration. J Neurochem 70:198-209.

Yamasaki K, Sawaki M, Noda S, Muroi T, Takakura S, Mitoma H, Sakamoto S, Nakai M, Yakabe Y (2004) Comparison of the Hershberger assay and androgen receptor binding assay of twelve chemicals. Toxicology 195:177-186.

Young LJ, Lim MM, Gingrich B, Insel TR (2001) Cellular mechanisms of social attachment. Horm Behav 40:133-138.

(Accepted 15 April 2005)

(Available online 14 June 2005) 